\title{
Corrigendum: Divisions of labor in the thiamin biosynthetic pathway among organs of maize
}

\author{
Jiahn-Chou Guan 1, Ghulam Hasnain'2, Timothy J. Garrett ${ }^{3}$, Christine D. Chase ${ }^{1}$, \\ Jesse Gregory ${ }^{4}$, Andrew D. Hanson ${ }^{2}$ and Donald R. McCarty ${ }^{\text {** }}$
}

${ }^{1}$ Genetics Institute and Horticultural Sciences Department, Institute of Food and Agricultural Sciences, University of Florida, Gainesville, FL, United States, ${ }^{2}$ Horticultural Sciences Department, Institute of Food and Agricultural Sciences, University of Florida, Gainesville, FL, United States, ${ }^{3}$ Department of Pathology, Immunology, and Laboratory Medicine, College of Medicine, University of Florida, Gainesville, FL, United States, ${ }^{4}$ Department of Food Science and Human Nutrition, Institute of Food and Agricultural Sciences, University of Florida, Gainesville, FL, United States

Keywords: thiamin biosynthesis, comparative transcriptomics, maize development, pollen development, meristem metabolism

\section{A corrigendum on}

Divisions of labor in the thiamin biosynthetic pathway among organs of maize by Guan, J.-C., Hasnain, G., Garrett, T. J., Chase, C. D., Gregory, J., Hanson, A. D., et al. (2014). Front. Plant Sci. 5:370. doi: 10.3389/fpls.2014.00370

In the original article, there was a mistake in Figure 6 as published. The scale of the $y$-axis was a factor of 10 too large. The corrected Figure $\mathbf{6}$ appears below. The authors apologize for this error and state that this does not change the scientific conclusions of the article in any way.

The original article has been updated.

OPEN ACCESS

Edited and reviewed by:

Joshua L. Heazlewood,

University of Melbourne, Australia

${ }^{*}$ Correspondence:

Donald R. McCarty

drm@ufl.edu

Specialty section:

This article was submitted to

Plant Breeding,

a section of the journal

Frontiers in Plant Science

Received: 16 January 2018

Accepted: 29 January 2018

Published: 20 February 2018

Citation:

Guan J-C, Hasnain G, Garrett TJ,

Chase $C D$, Gregory J, Hanson $A D$ and McCarty DR (2018) Corrigendum:

Divisions of labor in the thiamin biosynthetic pathway among organs

of maize. Front. Plant Sci. 9:148.

doi: 10.3389/fp/s.2018.00148

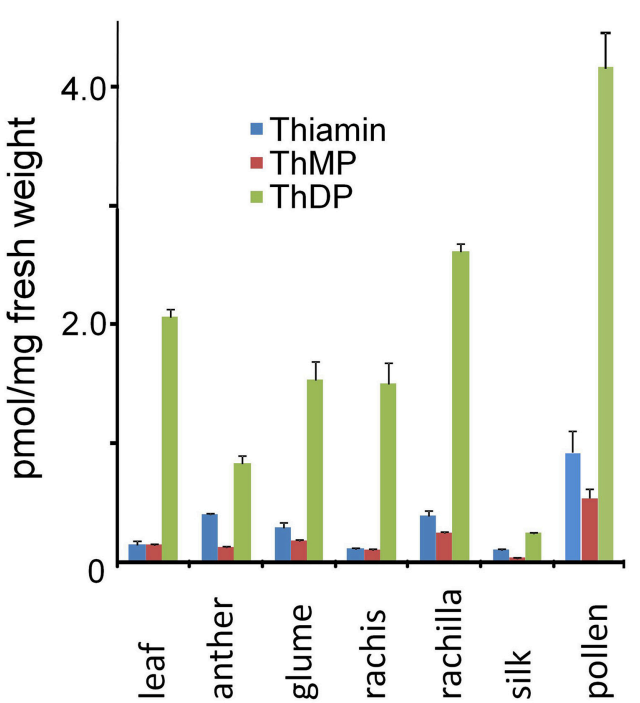

FIGURE 6 | Thiamin and thiamin phosphate ester contents of maize leaves, inflorescence and floral organs. Thiamin content (pmol/mg of FW tissue) was determined as described in Methods. Bars: Standard error of the mean, $n=3$.

Conflict of Interest Statement: The authors declare that the research was conducted in the absence of any commercial or financial relationships that could be construed as a potential conflict of interest.

Copyright () 2018 Guan, Hasnain, Garrett, Chase, Gregory, Hanson and McCarty. This is an open-access article distributed under the terms of the Creative Commons Attribution License (CC BY). The use, distribution or reproduction in other forums is permitted, provided the original author(s) and the copyright owner are credited and that the original publication in this journal is cited, in accordance with accepted academic practice. No use, distribution or reproduction is permitted which does not comply with these terms. 